\title{
Pelatihan Perencanaan Promosi Desa Wisata Kampung Paniis, Pandeglang Banten
}

\author{
Davis Roganda Parlindungan \\ Ilmu Komunikasi, Fakultas Bisnis dan Komunikasi \\ Institut Teknologi dan Bisnis Kalbis \\ Jalan Pulomas Selatan Kav. 22, Jakarta 13220
}

Email:davis@kalbis.ac.id

\begin{abstract}
One of the concepts that develop tourism objects through the community is known as Community Based Tourism (CBT). Where the concept of CBT is a manifestation of the active role of residents in developing aspects that have a tourist attraction in their area and have dominant authority in their management, wherein the end the impacts and benefits can be felt directly by residents, especially from the economic side. This community service activity is more focused on the village tourism sector which is managed by the local community under the name Paniis Lestari Group. The Paniis Lestari Group itself is one of the local community groups fostered by WWF-Indonesia which is located in Paniis Village, Taman Jaya Village, Pandeglang, Banten. The orientation of the group's activities is marine ecotourism in the marine sector and the conservation of biota. The training is carried out online via the internet network using the zoom application in the form of a videoconference with participants from the management and members of the Paniis Lestari community. In providing training materials, directions and suggestions are given to improve the abilities of the administrators and members in arranging tourism village promotion programs to be more focused.
\end{abstract}

Keywords: community based tourism, promotion programs, village tourism

\begin{abstract}
Abstrak: Salah satu konsep yang pengembangan objek wisata melalui komunitas dikenal dengan Community Based Tourism (CBT). Dimana konsep CBT ini merupakan wujud peran aktif warga lokal dalam pengembangan aspek-aspek yang memiliki daya tarik wisata didaerahnya serta memiliki otoritas yang dominan dalam pengelolaannya, dimana pada akhirnya dampak dan manfaat bisa dirasakan langsung oleh warga lokal tersebut terutama dari sisi ekonomi. Pada kegiatan pengabdian kepada masyarakat ini lebih fokus pada sektor wisata desa yang dikelola oleh komunitas warga lokal dengan nama Kelompok Paniis Lestari. Kelompok Paniis Lestari sendiri adalah salah satu kelompok masyarakat warga lokal yang dibina oleh WWF-Indonesia yang berlokasi di Kampung Paniis, Desa Taman Jaya, Kabupaten Pandeglang, Banten. Orientasi kegiatan kelompok ini sendiri adalah ekowisata bahari dibidang kelautan dan pelestarian alam biota. Untuk pelatihan dilakukan secara online melalui jaringan internet dengan menggunakan aplikasi zoom dalam bentuk videoconference dengan peserta dari para pengurus dan anggota komunitas Paniis Lestari. Dalam pemberian materi pelatihan diberikan arah dan saran untuk meningkatkan kemampuan para pengurus dan anggota dalam menyusun program promosi desa wisata agar lebih terarah.
\end{abstract}

Kata kunci: desa wisata, program promosi, wisata berbasis komunitas

\section{PENDAHULUAN}

Pariwisata merupakan salah satu sumber pendapatan alternatif daerah yang mampu membangkitkan ekonomi masyarakat desa selain pertanian, perkebunaan dan perikanan. Potensi dan keunikan disuatu daerah bila dikelola dan dikembangkan secara baik akan mampu mengangkat derajat kehidupan masyarakat desa sebagai daerah tujuan wisata. Seperti kita ketahui saat ini seudah banyak objek wisata di berbagai daerah banyak dikelola komunitas masyarakat lokal setempat. Tentunya dengan tata pengelolaan yang berbeda-beda sesuai dengan kemampuan dan pengalaman daerahnya masing- masing. Salah satu konsep yang pengembangan objek wisata melalui komunitas dikenal dengan Community Based Tourism (CBT) atau Wisata Berbasis Komunitas. Dimana konsep CBT ini merupakan wujud peran aktif warga lokal dalam pengembangan aspek-aspek yang memiliki daya tarik wisata didaerahnya serta memiliki otoritas yang dominan dalam pengelolaannya, dimana pada akhirnya dampak dan manfaat bisa dirasakan langsung oleh warga lokal tersebut terutama dari sisi ekonomi. Selain itu gagasan dalam konsep CBT ini lebih menekankan pada peran serta dan partisipasi aktif para warga lokal dalam mengelola kegiatan-kegiatan pariwisata didaerahnya (Setyowardhani et al., 2019). Sehingga konsep 
CBT sangat relevan dengan pengembangan atraksi pariwisata khas daerah di Indonesia. Dalam konsep CBT terdapat 2 (dua) aspek penting yaitu pertama, fokus CBT pada para pelaku utama adalah mereka yang berasal dari warga lokal setempat. Artinya warga lokal memiliki peran yang sangat penting sebagai sumber pengelola sekaligus aktor pelaku dalam pengembangan potensi daerah wisata tersebut. Posisi budaya lokal juga memainkan kedudukan yang sangat penting dalam berkontribusi sebagai aspek penting sebagai sumber potensi daerahnya yang harus dikelola dengan baik. Artinya pemanfaatan budaya lokal bisa dikembangkan dalam makna yang luas menjadikan produk pariwisata Indonesia sangat bermacam-macam dan beragam. Oleh sebab itu CBT sanggup menguatkan posisi warga dalam mendorong pertumbuhan dan perkembangan pariwisata dimasa yang akan datang. Pengembangan wisata berbasis komuniatas dari warga lokal mampu menjadi jalan keluar pemberantasan kemiskinan di daerah pedesaan. Karena sektor pariwisata yang berbasis pada komunitas warga lokal ini diharapkan mampu meningkatkan pendapatan ekonomi pedesaan serta memperluas setor baru di lapangan kerja bagi warga desa yang berkontribusi pada nilai kesejakteraan bagi masyarakatnya serta mampu mengatasi persoalan pengangguran dan penurunan populasi penduduk desa akibat arus urbanisasi warganya ke kota-kota besar. (Setyowardhani et al., 2019). Aspek kedua, pada kenyataannya berbagai atraksi serta sajian budaya lokal, baik dari seni suara, seni tari, tradisi lokal yang unik hingga kuliner khas daerah sangat diminati sebagian besar turis atau wisatawan yang berkunjung, baik dari dalam negeri maupun dari luar negeri. Untuk itu dalam menerapkan aspek CBT ini dapat dikelola secara maksimal (Pakpahan, 2018). Disamping itu, konsep wisata berbasis komunitas ini selain dapat membantu kehidupan dan roda ekonomi warga lokal, tetapi juga mampu meningkatkan kesadaran warga lokal akan arti penting pelestarian alam, budaya dan lingkungan hidup didaerahnya.

Faktor penting dalam penerapan konsep CBT adalah wajib dibarengi dengan pengembangan mutu sumber daya manusia (SDM), apalagi di daerah yang mana kawasan wisatanya yang masih dalam tahap berkembang sebagai desa wisata. Kerapkali, proses pengembangan desa wisata ini tidak diimbangi lewat kemampuan dalam identifikasi masalah-masalah SDM serta ketrampilan dalam perencanaan program wisata yang sungguh-sungguh. Pengembangan potensi wisata berbasis komunitas warga lokal dalam mengelola desa wisata tidak dibarengi dengan kemampuan identifikasi dan menganalisis permasalahan internal dan eksternal mereka, serta kemampuan dalam menyusun rencana dan strategi dalam pengelolaan yang perlu mereka lakukan. Dari hasil riset yang dilakukan oleh I Gede Sunarjaya, Made Antara, dan Dewa Putu Oka Prasiasa (2018) dipaparkan bahwa ketiadaan dalam kemampuan perencanaan dan manajemen pengelolaan desa wisata serta minimnya dukungan dari para pengampu kepentingan di daerah serta pihak-pihak yang berkontribusi langsung, hal ini menimbulkan kendala dan hambatan dalam mengembangkan sektor pariwisata berbasis komunitas lokal melalui wisata desa. Kemampuan dalam menyusun konsep dan perencanaan secara keseluruhan yang mencakup pengembangan sumber daya manusia, pemasaran, promosi, keuangan, fasilitas dan sarana penunjang, hingga identifikasi masalah dan menentukan faktor pendorong dalam partisipasi serta keterlibatan masyarakat di daerah wisata yang mereka kelola sangat penting. Hasil riset lain yang berhubungan dengan potensi desa wisata dilakukan oleh Tunjung Wulan dan Parfi Khadiyanto (2013) diuraikan bahwa kemampuan yang minim dalam pengelolaan dan kualitas produk yang rendah merupakan permasalahan dalam pengembangan desa wisata. Selain itu, belum tersedianya sarana dan prasarana pendukung secara lengkap di kawasan daerah wisata tersebut serta masih minimnya sanitasi dan kondisi aksesbilitas yang masih sulit dijangkau karena terbatasnya alat transpotasi ke lokasi wisata. Dari hasil kedua riset ini digambarkan bahwa dalam pengembangan kawasan desa wisata harus menyiapkan sumber daya manusia, kemampuan mengelola, menyiapkan fasilitas dan prasarana pendukung serta mendorong partisipasi masyarakat desa sekitar melalui komunitas warga lokal melalui peran pendampingan sekaligus bimbingan dalam bentuk pelatihan yang selalu berkelanjutan dan ditangani serta dijalani secara serius oleh semua pihak yang berkepentingan dan terlibat penuh dalam kegiatan tersebut agar pengembangan sektor pariwisata di pedesaan melalui wisata berbasis komunitas warga lokal menjadi lahan bisnis yang menguntungkan, memiliki nilai lebih dan terarah, sehingga secara tidak langsung mampu mengerakkan roda ekonomi warga sehingga secara tidak langsung mampu meningkatkan taraf kehidupan dan kesejateraan masyarakat desa tersebut (Desa et al., 2020).

Salah satu yang kawasan desa akan sedang dikembangkan ke arah wisata berbasis komunitas ada di Kampung Paniis terletak di Desa Tamanjaya, 
Kecamatan Sumur, Kabupaten Pandeglang, Provinsi Banten. Kampung Paniis berada di Desa Tamanjaya yang sebagian daerah wilayahnya masuk kedalam wilayah zona pemanfaatan Kawasan Taman Nasional Ujung Kulon (TNUK) Banten. Kampung Paniis sendiri memiliki luas keseluruhan $\pm 866.760 \mathrm{~m}^{2}$ dengan luas wilayah huni $\pm 62.742 \mathrm{~m}^{2}$ serta untuk luas lahan persawahan kurang lebih $494.793 \mathrm{~m}^{2}$ dan $309.225 \mathrm{~m}^{2}$ yang masuk ke dalam zona wilayah Kawasan Taman Nasional Ujung Kulon, Banten. Sebagian besar pekerjaan penduduk desa di Kampung Paniis adalah petani dan sisanya ada yang bekerja di luar kampung dan sebagian lagi menjadi nelayan. Peta Wilayah Kampung Paniis, Kab. Pandeglang, Banten seperti pada Gambar 1.

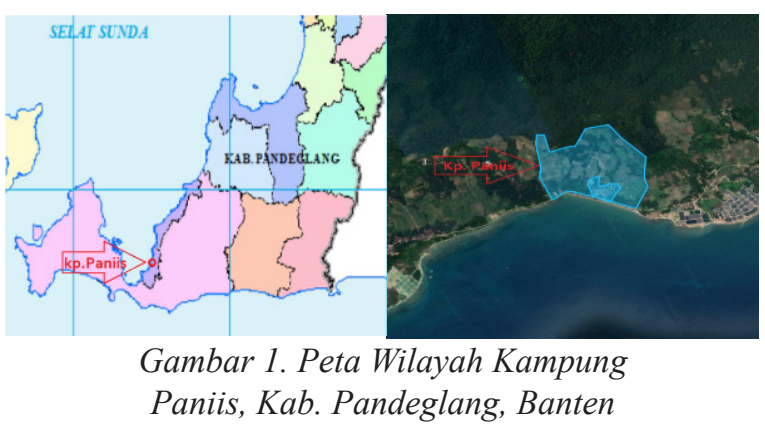

Kampung Paniis kebetulan berbatasan langsung dengan Taman Nasional Ujung Kulon yang memiliki potensi wisata yang begitu luas. Ada beberapa pulau disekitar taman nasional tersebut seperti Pulau Badul, Pulau Peucang dan Pulau Panaitan yang berada di sebelah barat Ujung Kulon memiliki potensi wisata bahari dan biota laut yang unik serta masih alami. Selain itu potensi ada objek wisata lain yang menariknya selain keindahan laut, yaitu Pantai Carita atau Tanjung Lesung, serta keunikan tradisi dan budaya masyarakat Kampung Paniis. (Detiknews. com, 2014). Sektor wisata ini masih dalam tahap pengembangan dimana nanti diharapkan mampu menjadi salah satu sektor alternatif sebagai sumber pendapatan bagi warga lokal disamping pertanian dan perikanan. Sektor wisata desa ini dikelola oleh komunitas warga lokal dengan nama kelompok Paniis Lestari. Paniis Lestari sendiri adalah salah satu kelompok masyarakat warga lokal yang dibina oleh WWF-Indonesia (World Wild Fund) yang berlokasi di Kampung Paniis, Desa Taman Jaya, Kabupaten Pandeglang, Banten. Orientasi kegiatan kelompok ini sendiri adalah ekowisata bahari dibidang kelautan dan pelestarian alam biota. Kelompok Paniis Lestari ini dibentuk dari tahun 2006 yang fokus pada aktivitas ekowisata bahari sekaligus konservasi alam disekitar Taman Nasional Ujung Kulon serta pemeliharaan biota laut khususnya terumbu karang sekitar Pulau
Badul. Selain itu kelompok ini juga menggelar pagelaran seni dan budaya pada saat musim panen dengan menyelenggarakan tradisi Sedekah Bumi dalam bentuk Pesta Tari Rengkong. Awal berdiri Kelompok Paniis ini diinisasi oleh WWF-Indonesia pada tahun 2006 yang bertujuan agar warga lokal tidak memasuki kawasan Taman Nasional Ujung Kulong untuk merusak dan mengeksploitasi sumber daya alam melalui pembalakan liar yang ada didalam kawasan taman nasional, sehingga dikuatirkan akan mempengaruhi populasi jumlah Badak Jawa (Rhinocheros Sondaicus) yang dilindungi oleh pemerintah dan telah terancam punah. Seiring perkembangannya, kelompok ini berkembang yang diharapkan mampu meningkatkan kesejahteraan dan roda perekonomian warga lokal setempat menjadi lebih baik melalui kegiatan ekowisata bahari dan pelestarian alam. Adapun kegiatan pariwisata yang ditawarkan oleh kelompok Paniis Lestari adalah :

\section{Wisata Bahari di Sekitar Wilayah Pulau Badul}

Para wisatawan yang berkunjung bisa merasakan suasana dan sensasi dalam menanam terumbu karang di sekitar pesisir wilayah Pulau Badul, Ujung Kulon Banten. Pengelola menyediakan berbagai keperluan untuk wisata bahari, mulai dari kapal yang akan membawa wisatawan ke Pulau Badul, peralatan diving dan snorkling serta aktivitas menanam terumbu karang. Disamping itu wisatawan juga disuguhkan pemadangan dasar laut dari kapal serta menikmati pemandang dipesisir pantai Pulau Badul. Dapat dilihat pada Gambar 2.

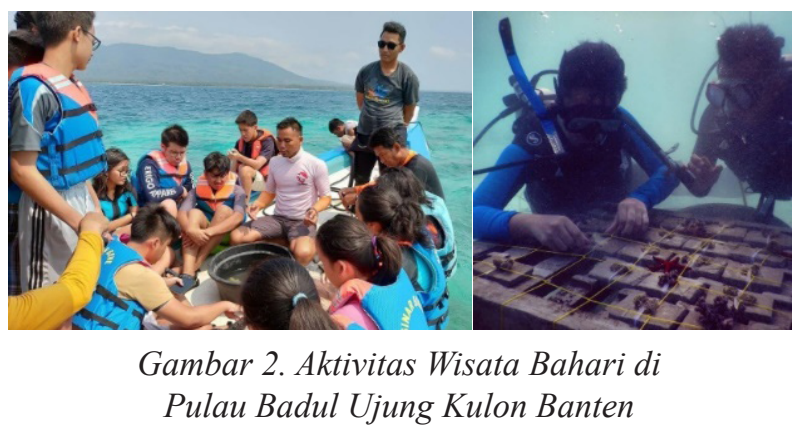

\section{Wisata Pagelaran Seni dan Budaya}

Sebagian besar masyarakat Kampung Paniis mata pencaharian utamanya adalah bertani. Setiap panen tiba mereka melakukan tradisi ritual Sedekah Bumi dengan menggelar atraksi seni budaya Tari Rengkong di adakan untuk menyambut pesta panen. Tarian ini sendiri ditampilkan sekitar 20 orang penari yang terdiri dari para ibu dan bapak warga Kampung Paniis secara berbaris membawa alu (alat penumbuk padi) sambil memukul-mukul lesung (tempat menumbuk padi) secara harmonis dan berirama. 
Sambil menari, seorang penari akan bernyanyi dengan lirik bahasa Sunda diikuti oleh penari lain sambil mengikuti irama dan berputar mengelilingi para penari lainnya yang sedang menumbuk padi. Dapat dilihat pada Gambar 3.

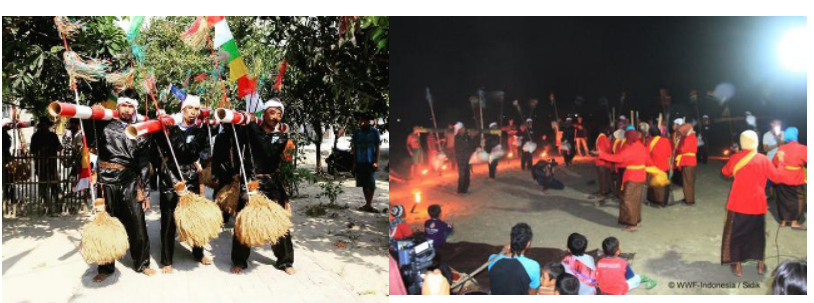

Gambar 3. Aktivitas pagelaran seni dan budaya

3. Homestay

Kampung Paniis juga juga menyediakan fasilitas dan sarana penginapan berupa Homestay dengan suasana ciri khas rumah sederhana di pedesaan pesisir pada umumnya serta disediakan makan sebanyak $3 \mathrm{x}$ sehari. Seperti pada Gambar 4.

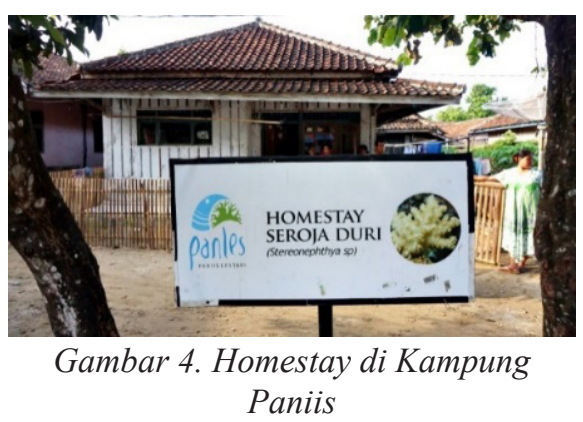

\section{METODE PELAKSANAAN}

Tim Dosen dan Unit Community Service dari Kalbis Institute mengadakan kegiatan Pengabdian Kepada Masyarakat (PKM) dalam bentuk pelatihan kepada para pengurus komunitas Paniis Lestari. Namun karena kondisi saat pelaksanaan pelatihan sedang dilanda wabah Pandemi Covid-19 di Indonesia dan seluruh dunia, sehingga tidak mungkin dilakukan kunjungan ke lokasi dan tatap muka langsung kepada para peserta latihan. Akhirnya diputuskan kegiatan pelatihan dilakukan secara online melalui jaringan internet dengan menggunakan aplikasi zoom dalam bentuk videoconference. Waktu pelaksanan dilakukan selama satu minggu yaitu dari tanggal $22-27$ Januari 2021 dengan peserta dari para pengurus komunitas Paniis Lestari.

Dalam pelaksanaan PKM dalam pelatihan ini, penulis memaparkan materi tentang menyusun program promosi desa wisata. Sebelum melakukan pelatihan tersebut, tim dosen dan tim dari unit Community Service Kalbis Institute mengadakan pertemuan sebanyak dua kali. Pertemuan pertama dengan tim Sekolah Relawan yang selama ini mendampingi dan membina para anggota komunitas Paniis Lestari. Isi pertemuan adalah pihak Sekolah Relawan menjelaskan dan memberi gambaran profil masyarakat serta kondisi geografis dari Kampung Paniis dan keberadaan dari komunitas Paniis Lestari. Lalu pada pertemuan kedua dilakukan dengan salah satu pengurus Komunitas Paniis Lestari dan staf dari Sekolah Relawan.

Kedua pertemuan ini dilakukan dengan metode wawancara yang dilakukan secara online melalui videoconference aplikasi zoom. Selanjutnya tim dosen melakukan persiapan dengan mencari data dan informasi melalui metode pencarian data sekunder digital terkait dengan Kampung Paniis dan Komunitas Paniis Lestari memalui website dan sosial media. Seluruh informasi dan data yang diperoleh, selanjutnya dianalisis serta dirangkum lalu diskusikan bersama tim dosen. Hasilnya dalam bentuk notulen/ catatan, informasi dari media sosial baik itu tulisan maupun video terkait dengan Kampung Paniis serta aktivitas promosi yang telah mereka lakukan selama ini. Atas dasar hasil tersebut lalu dilanjutkan merancang materi pelatihan yang akan diberikan kepada para peserta.

Setelah mendapatkan gambaran dari permasalahan yang dihadapi oleh pengurus Paniis Lestari, dari tim dosen Kalbis Institute juga mengadakan pertemuan untuk merancang topik materi apa saja yang akan diberikan dalam pelatihan tersebut yang sesuai kebutuhan dan keperluan mitra. Akhirnya disepakati untuk topik yang akan diberikan adalah sebagai berikut city branding, komunikasi pemasaran, event wisata, konsep kreatif, dasar-dasar fotografi dan videografi, copywriting dan public speaking, storytelling dan konten kreatif media digital. Khusus pelatihan merancang program promosi desa wisata meliputi rangkaian materi tentang perencanaan program komunikasi pemasaran di bidang pariwisata yang berisi : pertama, identifikasi target sasaran, analisis SWOT, kedua, menentukan tujuan komunikasi pemasaran, ketiga, menentukan strategi dan taktik, empat, menyusun anggaran (budgeting), kelima, melakukan evaluasi efektifitas (Sulaksana, $2010: 38$ )

\section{HASIL DAN PEMBAHASAN}

Dari hasil wawancara dalam pertemuan dengan staf Sekolah Relawan dan pengurus Paniis Lestari disampaikan bahwa para pengurus komunitas Paniis 
Lestari sejauh ini sudah memanfaatkan media sosial sebagai alat promosi seperti Facebook, Instagram dan Youtube, namun masih kurang maksimal dalam pemanfaatan dan kualitasnya sehingga menurut mereka masih terasa sangat kurang, hal ini dikarenakan kesulitan mereka dalam merancang program promosi daerah wisata yang memiliki daya tarik dari Kampung Paniis, mendesain iklan promosi dan brosur yang baik dan menarik, membuat video promosi, keterbatasan ketrampilan dan sarana serta peralatan pendukung, selain itu kurangnya kemampuan dalam Bahasa Inggris apalagi jika ada kunjungan turis dari mancanegara, dimana mereka sering kewalahan, makanya lebih sering memanggil orang diluar komunitas yang bisa menterjemahkan bila mengalami kendala Bahasa Inggris.

Serta kesulitan dalam membuat tulisan dalam Bahasa Inggris untuk kepentingan promosi melalui media sosial. Selain itu dijelaskan juga bahwa komunitas ini telah dibentuk pada tahun 2006, namun pada awal berdiri kurang berjalan, sehingga dibantu oleh WWF dalam pembinaan dan pendampingan serta penguatan organisasi yang akhirnya hingga saat ini masih berjalan dan beranggotakan sebanyak 20 orang. Fokus kelompok ini pada aktivitas ekowisata bahari sekaligus kegiatan konservasi alam disekitar Taman Nasional Ujung Kulon serta pemeliharaan biota laut khususnya terumbu karang sekitar Pulau Badul. Seiring perjalanan waktu mereka juga menggelar pagelaran seni dan budaya pada saat musim panen untuk menjaga tradisi Sedekah Bumi dalam bentuk Pesta Tari Rengkong. Komunitas ini kedepan diharapkan mampu meningkatkan kesejahteraan dan roda perekonomian warga lokal setempat menjadi lebih baik melalui kegiatan ekowisata bahari dan pelestarian alam, khususnya disekitar Kawasan Taman Nasional Ujung Kulon yang berbatasan dengan Kampung Paniis, Pandeglang Banten.

Dalam pemberian materi pelatihan diberikan saran untuk meningkatkan kemampuan para pengurus dalam menyusun program promosi wisata agak aktivitasnya lebih terarah. Seperti diketahui merancang program promosi tidak bisa dilepaskan peran komunikasi pemasaran yang terdiri beberapa elemen komunikasi pemasaran ketika memasarkan sebuah produk/jasa, termasuk dibidang pariwisata. Seperti elemen direct marketing, sales promotion, personal selling, public relations dan advertising. Tujuan sendiri komunikasi pemasaran itu sendiri memiliki tiga bagian, pertama yaitu untuk memberikan wawasan dan pengetahuan kepada konsumen, serta merubah sikap konsumen sasaran, juga memberikan tingkat kepuasan konsumen serta menjaga hubungan baik dengan konsumen. Untuk itu pesan yang disampaikan harus memberikan informasi yang mampu meyakinkan dan memuaskan konsumen (Widyastuti, 2017).

\section{SIMPULAN}

Pelaksanaan kegiatan pengabdian kepada masyarakat ini telah dilakukan secara lancar, nantinya diharapkan mampu memberi manfaat pada para peserta khususnya pada komunitas paniis lestari. Para peserta dari paniis lestari agar mampu dalam membuat dan menyusun program promosi yang efektif dan tepat guna khususnya promosi desa wisata Kampung Paniis, Pandenglang Banten melalui membidik target sasaran wisatawan lokal maupun mancanegara, menentukan tujuan promosi serta strategi dan taktiknya, menyusun biaya promosi dan pemanfaatannya serta evaluasi terhadap program promosi yang telah berjalan di Kampung Paniis, Pandeglang Banten.

\section{DAFTAR RUJUKAN}

Desa, K., Di, W., Wahid, A., \& Ashton, N. (2020). Social Capital And Civil Participation In The Development Of Village Tourism Area In Lombok Modal Sosial Dan Partisipasi Warga Dalam Pembangunan. 3(1), 81-100.

Detiknews.com. (2014). Menengok Desa Wisata Paniis di Pinggir Taman Nasional Ujung Kulon. Detiknews. Com. https://news.detik.com/berita/d-2578927/ menengok-desa-wisata-paniis-di-pinggir-tamannasional-ujung-kulon

Pakpahan, R. (2018). IMPLEMENTASI PRINSIP PARIWISATA BERBASIS KOMUNITAS DI DESA WISATA NGLINGGO YOGYAKARTA. Jurnal Master Pariwisata (JUMPA). https://doi.org/10.24843/ jumpa.2018.v05.i01.p07

Setyowardhani, H., Susanti, H., \& Riyanto. (2019). Optimalisasi Media Sosial sebagai Alat Promosi untuk Desa Wisata Lebakmuncang. Dinamisia : Jurnal Pengabdian Kepada Masyarakat, 3, 19-26. https://doi. org/10.31849/dinamisia.v3i2.2848

Widyastuti, S. (2017). Manajemen Komunikasi Pemasaran Terpadu : Solusi Menembus Hati Pelanggan (I. Hadi (ed.); Edisi Pert). Fakultas Ekonomi dan Bisnis Universitas Pancasila. www.univpancasila.ac.id 